\title{
HEALTH AND MARRIAGE BREAKDOWN: EXPERIENCE OF A SAMPLE OF DIVORCED WOMEN
}

\author{
ROBERT CHESTER \\ Department of Social Administration, The University, Hull
}

The termination of a marriage by death or separation precipitates individuals into new roles and social situations, and it has long been assumed that this experience may create exceptional vulnerability to medico-social disorders. Stein and Susser (1969) have suggested that this vulnerability is created by the transitional event rather than by the continuing new situation. As a means of approaching the general question, this paper examines the self-reported health experience of a sample of female divorcees. The findings support the notion that transitions in marital status are causally related to morbidity, and suggest also that the general practitioner may be strategically situated to mediate in situations of marriage breakdown.

Some students have been interested in the comparison of divorce and bereavement (Waller, 1951; Goode, 1964) because these situations share certain structural characteristics and because both may be emotionally disorganizing experiences. Theorizing, however, has not gone beyond the description of similarities and differences and the suggestion that the divorcee lacks the social support and welldefined role which western culture affords the widow. Even with current liberal social attitudes divorce is likely to be attended by a degree of moral obloquy and feelings of guilt or inadequacy, so that divorcees might perhaps be expected to undergo more personal disorganization than widows. Such comparisons, however, are currently prevented by the absence of appropriate studies. There are very few studies of the effects of divorce on health, and while studies of widowhood are more numerous some have unsatisfactory features and most concentrate on death or serious mental illness to the exclusion of lesser morbidity. Stein and Susser (1969) have reviewed many of the recent studies of the pathology of widowhood in the course of their own analysis of the relationship between bereavement and the inception of mental illness. More general morbidity among widows has been examined in an unquantified fashion by Marris (1958), who concluded that physical health was demonstrably worse after bereavement in half his cases, with some emphasis on psychosomatic disorders. Goode (1956) provides one of the few accounts of personal disorganization among divorcees, and his finding that the time of greatest disturbance coincided with separation supports the notion that transition into a less eligible marital state is related to morbidity. Marsden (1969) comments that marriage breakdown produces ill health, but his finding is unquantified, and divorcees are not distinguished from other categories of unsupported mothers.

\section{The Present Study}

The data presented in this paper are drawn from the interview responses of 150 women questioned in a sample survey of women who petitioned for divorce in Hull during 1967/70. The full sample consisted of the first 100 women who petitioned between October and March inclusive in each of the periods 1967-68, 1968-69, and 1969-70, representing approximately half the female petitioners between October 1967 and March 1970. There are no established seasonal factors in divorce, and it is believed that the method of sampling by time-band is methodologically acceptable (Goode, 1956). The cases analysed were the first 50 completed interviews in each time-band, and there was no systematic bias in the sequence of interviewing. These cases were abstracted for manual analysis in connexion with their interest for other investigations currently taking place.

It should be noted that those interviewed in the survey are petitioners for divorce. They do not therefore include women who may have left their husbands to live with another man, since such women would virtually always appear as respondents to male petitions for divorce. It would be interesting to examine the health experience of deserting wives for comparative purposes, but no way is known of listing or tracing such cases, and the present research does not bear on this issue. Thus all the women concerned here had deemed themselves to be the offended parties. The style of parting varied within the sample, but where it was the woman who left the marital home this was normally to move to inde- 
pendent accommodation or to live with relatives, and there seems no health difference related to this. In the present connexion, it is noteworthy that in recent years women have formed an increasing proportion of petitioners for divorce. This rising trend does not appear to be levelling off, and currently women are responsible for nearly two-thirds of the total petitions (Chester, 1970).

The sample cases had, when interviewed, been divorced for periods ranging from six months to three years, and it needs to be recognized that the information derives from patients' reports after varying periods of time rather than from clinical records. These reports may be variously deficient as medical histories, but there seems no reason to doubt the honesty of the responses, and there emerges clearly a picture of a considerable volume of distress.

\section{EFFECTS ON HeALTH}

The women were asked if the marriage breakdown had affected their health in any way, and only 20 of the 150 claimed to be unaffected. It is intended hereafter to concentrate on the majority who did report health effects, but it should be noted that the minority who denied such effects did commonly report experience of certain possible symptoms of stress which were asked about separately, such as weight changes, insomnia, loss of concentration, etc. It seems possible that this group saw such phenomena as 'natural' consequences of their situation and did not define them in health terms.

The other 130 divorcees did claim health effects, and the majority (101) also claimed to have visited a doctor in consequence. Treatment lasting less than six months was reported by $28 \%$ of the latter, and it seems likely that most of the further $25 \%$ who gave unquantifiable answers also fell into this category. Only $6 \%$ reported no treatment, and $25 \%$ claimed durations of two years or more. Clearly the symptoms were not merely transient in many cases, and the survey responses suggest that they were also far from trivial, at least as perceived by the sufferers. Feelings of hopelessness, desolation, shock, bitterness, failure, and insecurity are mentioned, and although a measure of the severity of the symptoms cannot be attempted an inspection of the full responses makes it clear that the experience of marriage breakdown is traumatic for most women.

This conclusion is supported by the nature of the symptoms which are reported, most of which are familiar in discussions of psychosomatic disorders. Headaches and dizziness, skin rashes and irritations, falling hair, abscesses, asthma, anorexia, and pains in the chest and stomach are among the conditions mentioned, and it seems reasonable to infer that these reflect the strain of emotional disruption, and of the economic deprivation which many also suffer. The most common conditions experienced, however, are described in such terms as 'nerves', 'nervous tension', 'nervous troubles', and, more specifically, 'depression'. Approximately half the group expressed their conditions solely in such terms, and although the remainder mentioned specific physical distress very few complained of this alone. Some who reported nervous troubles did so specifically in terms of their manifestations, such as repeated blinking, agitation, extreme irritability, etc. Few mentioned only one effect, and mention of four or five was not uncommon.

Apart from the open-ended health question, the women were asked about experience of a list of eight specific effects which are often seen as symptomatic of stress, viz.,

(i) serious weight change (gain or loss)

(ii) sleep difficulties

(iii) beginning to smoke, or smoking more heavily

(iv) beginning to drink, or drinking more heavily

(v) difficulties with concentration

(vi) tendency to weep

(vii) tendency to excessive tiredness

(viii) tendency to self-neglect.

Such symptoms were widely experienced. A Table I shows, only 6 of the 130 women experienced none of them, and $80 \%$ claimed at least four.

The frequency with which each symptom was claimed is shown in Table II, which also shows the rank order of frequency.

The first four items were thus each claimed by $70 \%$ or more of the women, and smoking and self-

TABLE I

NUMBER OF SYMPTOMS CLAIMED BY WOMEN WHO EXPERIENCED HEALTH EFFECTS $(N=130)$

\begin{tabular}{l|l|l|l|l|l|l|l|l|l|l}
\hline & \begin{tabular}{l} 
No. of Symptoms \\
\hline No. of women
\end{tabular} & 3 & $\frac{2}{4}$ & $\frac{3}{12}$ & $\frac{4}{25}$ & 5 & 6 & 7 & 8 & 0 \\
\hline
\end{tabular}

TABLE II

FREQUENCY OF REPORT FOR EACH SPECIFIED SYMPTOM

\begin{tabular}{l|c}
\hline \multicolumn{1}{c|}{ Symptom } & Frequency \\
\hline Crying & 104 \\
Weight & 101 \\
Sleeping & 96 \\
Tiredness & 91 \\
Concentration & 80 \\
Smoking & 66 \\
Self-neglect & 65 \\
Drinking & 9 \\
\hline
\end{tabular}


neglect by $50 \%$. The low figure for drinking may reflect concealment because of cultural taboos concerning alcohol in general and female drinkers in particular. There may also be some underreporting of smoking and self-neglect, the former because of the self-deception of smokers, and the latter because of its negative connotations of 'letting oneself go'. Where it is reported, selfneglect may sometimes be connected with weight changes, since a frequently cited manifestation was failure to arrange proper meals or diet. (A disturbing possibility here is that some children may also suffer in their diet.) However, some of the reported weight changes were very severe, being measured in stones, and it seems probable that in many cases this was anorexia associated with depression rather than with simple self-neglect.

\section{TIMING OF THE SyMPTOMS}

The interviews sought to elicit when health effects were experienced in relation to the process of marriage breakdown and divorce. In respect of general health and, separately, of the eight specific items the respondents were given a choice of six time periods which seemed of possible significance, and were asked to indicate when the effect was at its worst.

The time periods were:

1. during marriage troubles before separation;

2. at separation or just after;

3. when the final decision was made to divorce;

4. at the time of divorce court hearing, or just after;

5. at the time of interview;

6. never, not applicable.

Table III shows the distribution of responses and leaves no doubt that the traumatic impact of the divorce process is strongly concentrated on the latter period of marriage and the early separation period.

Clearly the time of the decree and after-the 'post-divorce period'-is not the time of maximum

TABLE III

WHEN SYMPTOMS WERE AT THEIR WORST

\begin{tabular}{|c|c|c|c|c|c|c|}
\hline Symptom & Marriage & $\begin{array}{c}\text { Separa- } \\
\text { tion }\end{array}$ & Decision & Divorce & $\begin{array}{l}\text { Inter- } \\
\text { view }\end{array}$ & Never \\
\hline \multirow[t]{2}{*}{$\begin{array}{l}\text { Crying } \\
\text { Weight } \\
\text { Sleeping } \\
\text { Tiredness } \\
\text { Concentration } \\
\text { Smoking } \\
\text { Self-neglect } \\
\text { Drinking } \\
\begin{array}{l}\text { General health } \\
\text { effects }\end{array}\end{array}$} & $\begin{array}{r}63 \\
58 \\
57 \\
50 \\
45 \\
39 \\
38 \\
6\end{array}$ & $\begin{array}{r}29 \\
35 \\
30 \\
29 \\
22 \\
18 \\
19 \\
3\end{array}$ & $\begin{array}{l}5 \\
6 \\
6 \\
7 \\
8 \\
5 \\
2 \\
0\end{array}$ & $\begin{array}{l}5 \\
1 \\
0 \\
2 \\
2 \\
2 \\
3 \\
0\end{array}$ & $\begin{array}{l}2 \\
1 \\
3 \\
3 \\
3 \\
2 \\
3 \\
0\end{array}$ & $\begin{array}{r}26 \\
29 \\
34 \\
39 \\
50 \\
64 \\
65 \\
121\end{array}$ \\
\hline & 75 & 36 & 7 & 10 & 2 & 0 \\
\hline
\end{tabular}

impact, a finding which accords with that of Goode (1956). The distribution curve is the same shape for all items, and the few admitted cases of drinking are all concentrated in the late marriage and early separation periods. The time periods shown are not necessarily in chronological order for each individual respondent. They represent events in a process which can unfold in a number of ways, although for most cases they are in fact in chronological order. The impact of the separation per se is probably understated by the table, since detailed inspection of the responses makes clear that while some women were referring to the latter period of marriage in general, others were referring to the very latest stage, when separation was contemplated and imminent.

\section{REPORTED TREATMENT}

The nature of the symptoms which took the divorcees to the doctor is reflected in the treatments reported. Some of these relate to specific physical symptoms, such as ointments for skin rashes, and a few respondents claimed they received no treatment other than advice to 'pull themselves together'. In $60 \%$ of cases, however, tranquillizing drugs were mentioned, and the other most commonly reported treatments were sedatives and tonics. Psychiatric treatment was mentioned by a small number, with $6 \%$ claiming a period of in-patient care in a mental hospital. There was little reference to counselling, and it seems that for a majority drugs were utilized as a coping mechanism. For some this was a relatively short-term measure, but 20 of the 26 women who claimed treatment for two years or more mentioned tranquillizers or sedatives, and it would appear that for them coping had become considerably dependent on drugs, a situation also found by Marsden (1969).

\section{Discussion}

The above findings, although dependent upon selfreporting, show that marriage breakdown is attended by a considerable volume of stress for women which manifests itself in medical or quasi-medical terms, and that symptoms tend to be concentrated on the periods when separation is imminent or immediate. This lends support to the notion that transition in status is closely related to personal disorder, and shows that when marriages are dissolved it is not the divorce but the earlier separation which has most impact. This is not, perhaps, surprising since it is the separation which has the more momentous implications for daily life. When the common household is broken up each partner is faced with the disruption of accustomed routines. New households have to be 
established, new patterns of economic and social life created, and new decisions made. Sexual access to one another is ended, although the importance of this will partly depend on the quality of the sexual relationship before the separation. Thus in various ways the disorganizing impact of marriage breakdown is concentrated on the separation and its antecedent events. It has been shown (Chester, 1971) that the interval from separation to divorce is characteristically lengthy, with a median of 2.9 years, and thus by the time divorce is reached there has been much time for adjustment and the divorce itself has relatively little impact.

So far as the survey respondents were concerned it seems likely that the stress symptoms arising from marriage breakdown were dealt with largely within a medical frame of reference. In defining such situations only or principally in medical terms it is possible that general practitioners are denying themselves the opportunity to help patients within a wider framework. As stated, counselling was rarely reported and there was little evidence of referral to other agencies. It has been shown, however (Goldberg, Neill, Speak, and Faulkner, 1968), that within general practice there is a large potential field of work for social workers or for agencies upon which social workers can call. The report showed that divorced and separated wives formed $9 \%$ of the referrals from doctor to social worker and thus demonstrated that in a general way there is potential scope for a doctor to call upon extra-medical resources in the helping process where marriage breakdown is concerned. More specifically, however, the data above suggest that the general practitioner may be strategically located to facilitate the reconciliation of separated spouses.

Under the divorce law effective from 1971 a solicitor may be required to certify that he has discussed with a petitioner the possibility of reconciliation. However, by the time she sets a petition in motion a women has committed herself to divorce, and both on a priori grounds and interview evidence it seems probable that conciliation efforts at this stage will be nugatory. It is not easy to find grounds for optimism about prospects for reconciliation facilities at any stage of the marriage breakdown process, but clearly prospects are better before there is a commitment to divorce, and it is this which gives the doctor his potentially strategic role. Responses from another section of the interview show that $85 \%$ of the women had not decided upon a divorce until after the separation. Since the interval from separation to divorce is lengthy, and since maximum trauma is concentrated around the separation, a situation is created whereby a high proportion of those theoretically available for reconciliation seek medical help at a time before they have made a commitment to divorce. The general practitioner is likely to be the first 'official' person that the woman meets in a helping context, and, while the scope must not be exaggerated, may thus have a prime opportunity, by direct counselling or referral, to facilitate reconciliation. Even short of effective reconciliation there is much that can be done to support people in these vulnerable circumstances and to mitigate the consequences of marriage breakdown for those concerned, including any children.

While there are some doctors who already associate themselves with marriage guidance (Metcalfe, 1970), there may be some who feel that concern with a patient's marital affairs is outside their brief and others who feel this to be outside their strictly professional competence. The report of the experiment at the Caversham centre (Goldberg et al., 1968) assumes significance because it shows how a social worker can offer counselling skills and knowledge of social agencies which a medical practitioner may feel he does not possess. Appropriate evaluation and referral are regarded as vital by a consultant ex8 perienced in marriage guidance (Dominian, $196 \&$ and the skill to relate the problem to an agency is part of the social worker's armoury. The Cavershant experiment confirms that patients with marriage difficulties are prone to present vague symptoms not initially acknowledged to have a marital component, and while no reference is made to reconciliation the potentiality of this may be present when there is early referral to a social worker.

It is also possible that a medical setting may be a suitable locus for initial contact in marriage guidance, since the use of such a setting is less classlinked than some others. The two major agencies for marriage conciliation are the Probation Service and the Marriage Guidance Councils. The former is likely to be shunned by middle-class individuals, and the latter possess a middle-class aura which may discourage approaches by working-class people. The medical setting is relatively neutral in this respect, and likely to be both acceptable to the middle class and accessible to the working class. Thus a potential clientele for counselling and other help is available from those who, for whatever reason, do not approach formal conciliation agencies. It might also be noted that a medical setting may offer possibilities for clinical research into marriage breakdown which can be based on wider samples than simply those who actively seek conciliation facilities. 


\section{SUMMARY}

The results are shown of an analysis of the selfreported health experience of a sample of female petitioners for divorce. The findings show that the majority of respondents experienced a deterioration of health, with an emphasis on symptoms that are presumptively related to stress. The timing of the health effects suggests that the maximum disturbance is associated with the latter stages of marriage and the separation rather than with the divorce action, and that drug therapy is the most common form of treatment.

It is suggested that the findings support the notion that morbidity is causally related to transition from married status. It is also suggested that general practitioners may be strategically located to mediate in situations of marriage breakdown, possibly by referral to social workers.

The findings reported above come from research which has been financed by the Eugenics Society, the Social Science Research Council, and the Department of Health and Social Security, to whom my thanks are due.

I am grateful to Dr. J. Dominian of the Central Middlesex Hospital for his comments on a draft of the article. Naturally he bears no responsibility for its final form.

\section{REFERENCES}

CHESTER, R. (1970). Sex differences in divorce behaviour. In Biosocial Aspects of Sex: Proc. 6th ann. Symp. Eugenics Soc., London, 1969, ed G. A. Harrison and J. Peel. J. biosoc. Sci., Suppl. 2, 121.

(1971). The duration of marriage to divorce. Brit. J. Sociol., 22, 172.

Dominian, J. (1968). Marital Breakdown. Penguin, London.

Goldberg, E. M., Neill, J., Speak, B. M., and FAULKNER, H. C. (1968). Social work in general practice. Lancet, $2,552$.

Goode, W. J. (1956). After Divorce. The Free Press, New York.

(1964). The Family. Prentice-Hall, Englewood Cliff, New Jersey.

MARRIS, P. (1958). Widows and their Families. Routledge and Kegan Paul, London.

MARSDen, D. (1969). Mothers Alone. Allen Lane, London.

MetCALFE, D. H. H. (1970). A marriage guidance counsellor and general practitioner discussion group. J. roy. Coll. gen. Practit., 20, 107.

Stein, Z., and SusSER, M. (1969). Widowhood and mental illness. Brit. J. prev. soc. Med., 23, 106.

WALLER, W. (1951). The Family, revised edition, revised by R. Hill. Holt, Rinehart and Winston, New York. 